\title{
SOCIALISMO Y DEMOCRACIA HACIA EL NUEVO SIGLO
}

\author{
Eduardo Lucio Molina*
}

\begin{abstract}
Disipado en parte el delirio maníaco-triunfalista de la derecha tras el colapso soviético, la reflexión sobre la clausura del 'socialismo real' y el desafío de la revolución científico tecnológica en curso comienzan a generar promisorios espacios de lucha política y reflexión teórica. No carece de cierta lógica perversa la coincidencia entre el anuncio del 'fin de la historia' ${ }^{1}$ y la pretensión de archivar para siempre las concepciones que hacen de la igualdad de oportunidades, la equidad social y una democracia digna de ese nombre el eje no sólo de un futuro deseable sino, considerando la actual encrucijada ecológica, de la propia supervivencia de la civilización. La aporía de la civilización industrial en pugna con la preservación de los recursos naturales, esa amenaza creciente que llega del futuro y cuya toma de conciencia coincidió con el viraje histórico hacia el 'pensamiento único’, pone de manifiesto ante todos, con más claridad que nunca, que “el capitalismo constituye actualmente un obstáculo de grandes proporciones para la resolución de los males que ha producido su propio desarrollo". ${ }^{2}$ A su vez, los rotundos fracasos de la socialdemocracia moderada la han revelado más como una forma de adaptación al capitalismo que como una propuesta de transformación radical del orden

* Escritor y periodista argentino.

${ }^{1}$ Francis Fukuyama, The end of history and the last man, 1992, Londres, Hamish Hamilton.

${ }^{2}$ Ralph Miliband, Socialismo para una época de escépticos, México, Siglo XXI.
\end{abstract}


EDUARDO MOLINA

social. Por lo demás, la identificación lisa y llana del socialismo revolucionario con la totalidad del proceso que desembocó en la degeneración y burocratización de la uRss a partir de la experiencia stalinista -vaticinadas por Lenin y Trotsky ya en la segunda década del siglo xx como una derivación inevitable del posible y luego efectivo aislamiento de la revolución bolchevique-, no hace sino confundir y tergiversar el debate.

Al igual que todo proyecto histórico, el socialismo sólo puede probar su viabilidad y superioridad mediante una construcción práctica que en el caso inaugurado en Rusia no se consumó o terminó siendo una caricatura, pero ello no lo cancela como propuesta de utopía realizable. La degradación y el derrumbe soviético, así como las transformaciones del capitalismo y del mundo en su conjunto tras la derrota del nazifascismo, afectaron naturalmente a todas las corrientes socialistas, desde las ‘ortodoxas’ hasta las críticas, y dieron origen en muchos casos a múltiples y variadas revaloraciones acerca de los problemas y las vías actuales de la empresa socialista. Se trata sin duda, y hoy es particularmente visible, no de una nueva sociedad alcanzable a corto plazo de una vez y para siempre, sino de un prolongado proceso histórico sujeto a constantes correcciones y perfeccionamientos, un proceso abierto a nuevos y hoy imprevisibles desarrollos. Las metas sucesivas de este largo trayecto deben conducir a una democracia real y no formal y ficticia, una democracia sólo realizable mediante la drástica eliminación de las actuales desigualdades y discriminaciones sociales, lo que requiere como premisa básica la socialización de los medios fundamentales de producción y de cambio.

En rigor, la idea de democracia debería quedar subsumida en el concepto de socialismo, pero su tratamiento particular como algo separado obedece a menudo al hecho de que es el aspecto en que más temprana y profundamente mostró sus falencias y desviaciones el modelo soviético, el principal y más cercano intento de erigir una sociedad distinta a la capitalista. La ausencia de formas democráticas en la vida política caracterizó hasta tal grado a la URSS, considerada como símbolo del ‘socialismo realmente existente', que contrapuso 
SOCIALISMO Y DEMOCRACIA

ambos conceptos como polos recíprocamente excluyentes. Sólo analizando y extrayendo las correspondientes enseñanzas de la contradictoria experiencia inaugurada por la revolución bolchevique será posible afrontar desde tal perspectiva las nuevas condiciones de la lucha de clases, evitando la repetición de errores y fórmulas fallidas.

\section{El ciclo del 'socialismo real’}

El desplome soviético cayó sobre las cabezas de todas las corrientes de izquierda por igual, sin excepción alguna, y dañó incluso a los marxistas revolucionarios, a los trotskistas y a las alas menos reformistas de la socialdemocracia moderada, independientemente de las críticas y los deslindes que durante años y aun décadas tales sectores hayan formulado, pública y documentadamente, contra el 'socialismo burocrático' de corte staliniano, ese fenómeno degenerativo cuya raíz, sin embargo, algunos hacen remontarse hasta el propio origen del bolchevismo. Pero al mismo tiempo que destruyó falsas (y no siempre conscientes o confesadas) ilusiones de regeneración, fue evidente que el ocaso soviético liberó a la izquierda de cargar con el pesado lastre de esa versión inviable, gris y desencantada del 'socialismo real' para volver a pisar el suelo firme de lo que realmente merece llamarse socialismo.

Queda pendiente aclarar, como un interrogante a la propia ingenuidad de buena parte de la izquierda crítica, qué fue lo que alentó -a pesar de todo-su callada esperanza en una evolución positiva reconstituyente de la URSS hacia una 'revolución política' superadora de la herencia staliniana, qué le hizo suponer alguna vez que la tendencia predominante de la burocracia soviética podía tomar otro rumbo que no fuera el de una restauración precariamente actualizada del capitalismo. $^{3}$

${ }^{3}$ Cfr. Eduardo Lucio Molina y Vedia, "La clase trabajadora y los pobres del mundo a la defensiva”, Revista de la Universidad Autónoma del Estado de México, primavera de 1992. 
EDUARDO MOLINA

Desde su origen la humanidad vio abrirse paso gradualmente durante milenios, en medio de múltiples espejismos y tergiversaciones, la noción genérica del 'bien común' como una meta anhelada y factible, como un principio de acción eficiente, capaz de sustraernos a la amarga imagen de la existencia que sintetiza Macbeth, el personaje de William Shakespeare, en unas pocas palabras, hoy de inusitada actualidad: "El cuento de un imbécil, lleno de estrépito y furia, que no significa nada."

El hecho de que, al igual que la fugaz Comuna de París (marzoabril de 1871), la revolución bolchevique de 1917 en Rusia sólo pudiera desplegar de modo cabal por breve tiempo sus nuevas formas emancipatorias, no invalida la indiscutible realidad de que puso sobre la tierra un inédito proyecto de vida social, apuntando a motivaciones y valores cualitativamente superiores a todo lo antes conocido, de una riqueza y una amplitud de miras sin precedentes. Más allá de su colapso a fines de los años 80 (culminación de un fracaso muy anterior), y por encima de las falencias que siempre tuvo y de las aberraciones en que desembocó, el mundo insinuado en los primeros años de la revolución rusa constituyó la comprobación práctica en la escena social del carácter histórico, superable y obsoleto del modo de producción capitalista. Las nuevas formas de organización que instauraron los bolcheviques mostraron durante ese lapso una extraordinaria eficacia en condiciones completamente desfavorables, y son las que a la postre, durante más de medio siglo, posibilitaron hacer pasar al país más atrasado de Europa de los castigos corporales a los campesinos y el arado de madera a la energía nuclear y los vuelos espaciales.

El proyecto de Lenin y los bolcheviques contaba con una extensión exitosa de la ola revolucionaria a los principales países capitalistas de comienzos del siglo XX, fundamentalmente, en un principio, a Alemania, Austria-Hungría, el Reino Unido y Francia, y después al resto del mundo. ${ }^{4}$ El atraso de todo orden heredado del zarismo, el aborto de

${ }^{4}$ En palabras de Lenin, Rusia sólo era ‘el eslabón más débil’ por donde era posible quebrar la cadena de la dominación del capitalismo imperialista. 
los levantamientos en el centro de Europa y en Alemania, la guerra contra catorce ejércitos invasores y la oposición interna, el aislamiento y el bloqueo que le impuso el sistema imperialista, entre otros factores, hicieron pronto absolutamente imposible aplicar las enseñanzas de la Comuna de París, que según Karl Marx había revelado lo que era "en esencia el gobierno de la clase obrera, fruto de la lucha de la clase productora contra la clase apropiadora, la forma política, al fin descubierta, bajo la cual podía llevarse a cabo la emancipación económica del trabajo". 5

El consiguiente proceso soviético de degeneración y burocratización, previsto ya por Lenin ${ }^{6}$ y Trotsky explícitamente bajo tales circunstancias, fue alejando cada vez más a la URSS, desde mediados de los años 20, de aquellas premisas básicas: sustitución del ejército profesional por el pueblo armado, completa elegibilidad y permanente amovilidad de los funcionarios y magistrados (incluidos los jueces), eliminación de todos sus privilegios y establecimiento de su remuneración con el salario de un obrero calificado, laicización de la vida pública, suplantación del parlamentarismo deliberativo por una corporación de trabajo legislativa y ejecutiva a la vez, coordinación y centralización democrática del poder social mediante la destrucción del estado parásito y la erección en su lugar de un estado representativo de la inmensa mayoría del pueblo, en suma, la preparación de las premisas para la gradual extinción de un estado que, al ser del conjunto, no sería ya realmente tal. Todo ello, por supuesto, posibilitado y dotado de su pleno sentido y trascendencia real en el contexto y sobre la base concreta de la 'expropiación de los expropiadores’, a través de la transformación de la propiedad privada capitalista sobre los medios de producción y de cambio en propiedad social. ${ }^{7}$ Precisamente el deterioro y la desnaturalización

\footnotetext{
${ }^{5}$ Karl Marx, La guerra civil en Francia, 1871.

6 "Si nuestra revolución no se extiende de inmediato a Alemania, y enseguida al resto de Europa, se burocratizará y degenerará inevitablemente” (Lenin, 1918).

${ }^{7}$ Karl Marx, op. cit.
} 
EDUARDO MOLINA

del modelo soviético puede irse pautando por el abandono progresivo de dichas premisas mediante un continuo proceso involutivo: retiro de las armas al pueblo para confiárselas con exclusividad a fuerzas armadas regulares, crecientemente aisladas de la sociedad en su conjunto; formación de una capa o estrato burocrático inamovible con características de 'aparato' de estado; clausura de la libertad de expresión; establecimiento de privilegios salariales y de todo tipo para el funcionariado o 'nomenklatura'; sacralización (o sea desnaturalización) del marxismo, erigido en 'religión social', es decir, en un dogma incapaz de dar cuenta de la realidad; restitución de un parlamentarismo casi exclusivamente deliberativo y aun simbólico; conversión de la proclamada dictadura democrática (mayoritaria) del proletariado, el campesinado y el pueblo, en dictadura primero del partido, luego del comité central y finalmente de un autócrata; crecimiento gigantesco de un enorme aparato de estado parasitario y tiránico que encarnó a la nueva capa dominante, la burocracia en el poder; anulación de todo debate en el seno del partido, la sociedad y los medios masivos de difusión; despolitización acelerada de la opinión pública; etcétera.

Convertido en 'ciencia de estado', petrificada y dogmática, el 'mar12 xismo’ de cuño stalinista contaminó al movimiento comunista y revolucionario internacional con todas sus deformaciones, transformándolo en un apéndice del poder burocrático encarnado por el régimen imperante en la URSS, tras la imposible y reaccionaria consigna de defender ‘la construcción del socialismo’ en un solo país. Una de las consecuencias de esta involución fue la falta de apoyo y hasta el freno que buscó poner el movimiento comunista internacional a los intentos de transformación revolucionaria en el mundo capitalista. El proceso de burocratización llegó con Stalin a corromper al estado soviético hasta convertirlo en un feroz aparato de poder represivo, que eliminó físicamente a muchos de los mejores cuadros de la revolución bolchevique y a vastas masas de obreros, campesinos y gente del pueblo, ya sea mediante su ejecución o convirtiéndolas en víctimas de campos de trabajo. ${ }^{8}$

${ }^{8}$ Cfr. Alexander Soljenitsyn, El archipiélago Gulag. 
En tales condiciones no puede hoy sorprender que la burocracia dominante en el bloque soviético optara por reciclar las bases de su poder pasando de un discurso oficial 'socialista' vaciado de todo contenido a un retorno a la 'sociedad de mercado’. Así, la nueva burguesía postsoviética se nutre de los cuadros intelectuales, técnicos y políticos herederos del régimen staliniano. La reconversión capitalista de la sociedad rusa se produjo desde la cúpula, sin mayor resistencia de las masas populares, que no tenían, o no creían tener, prácticamente nada que añorar del antiguo régimen.

El politólogo Alejandro Horowicz resumió de la siguiente manera las causas y consecuencias del colapso comunista: "La victoria es irreemplazable. Ninguna explicación puede sustituirla. La Rusia soviética debía ser el prólogo de la revolución socialista europea. Si así no sucedía, estaba condenada. Y este dilema sigue presidiendo hoy la historia universal. El socialismo no puede sino ser el modo que la clase obrera se da para resolver sus problemas en la arena del mercado mundial. Cuando sucede otra cosa no siempre queda claro en presencia de qué estamos, y éste, debemos resignarnos, es un problema teórico a resolver. Algo sí queda claro, y es en presencia de qué no estamos. La capacidad de la clase obrera europea de autorganizarse ha mostrado serias, graves, terribles falencias. Y la dirección política de la Revolución rusa resultó destruida. A caballo de ambas derrotas el destino del socialismo y de la humanidad en su conjunto quedó en entredicho. Si la historia no consigue ser remontada, este fragmento derrotado será, en definitiva, la única posibilidad que fue capaz de construir la humanidad para salvarse de ese lujoso basural sanguinolento que es el capitalismo imperialista." 9

${ }^{9}$ Alejandro Horowicz, “El basural de lujo”, revista Crisis, diciembre de 1989, Buenos Aires. 
EDUARDO MOLINA

\section{La nueva guerra fría}

El mundo al que se reintegró el bloque soviético, seguido en el mismo camino por los comunistas chinos, se denomina a sí mismo eufemísticamente como "sociedad globalizada de mercado neoliberal”. Sin embargo, es básicamente un modelo conservador que, a la vez que difiere básicamente de los esquemas tradicionales de libre competencia, democracia representativa con voto universal obligatorio y soberanía de los estados nacionales, conserva y acentúa en lo sustancial un primado prácticamente excluyente de la iniciativa privada en el desarrollo de la economía y los asuntos públicos.

Un ejemplo de las renovadas concepciones del 'pensamiento único' imperante en escala mundial, como lo confirma el triunfo del conservadurismo texano de George Bush, es el Documento del Comité de Santa Fe IV. Allí este influyente grupo de intelectuales orgánicos de la derecha, expresión del complejo militar-industrial de la mayor potencia imperialista mundial, señala los nuevos flagelos a liquidar: los chinos, la mafia rusa, Cuba, el 'narcoterrorismo', la guerrilla colombiana y el presidente de Venezuela, Hugo Chávez, al que etiquetan como ‘dictador castrista’. También “el surgimiento de un militarismo izquierdista en los países andinos que finalmente está obteniendo un poco de atención por parte de los medios, en la medida en que el 'bolivarismo' se convierte en un grito de ataque de los comunistas y socialistas”.

"Lo inquietante de estas definiciones -afirma el periodista Miguel Bonasso- es que el think tank de Santa Fe está integrado por militares, espías, empresarios, diplomáticos y académicos estadounidenses que han vivido y trabajado en América Latina y tienen gran peso político, empezando por su líder, el general retirado Gordon Summer Jr., que presidió la Junta Interamericana de Defensa.” Y recuerda: “El Santa Fe I, de 1980, calificó al gobierno del general Omar Torrijos como 'dictadura nacionalista de extrema izquierda' y el líder panameño perdió la vida, poco después, en un accidente aéreo que nunca fue investigado. Otro ‘marcado' por el Santa Fe I, el primer mandatario 
de Ecuador Jaime Roldós, también se estrelló con el avión presidencial. En el Santa Fe II (de 1988) se decía textualmente: "El problema de Panamá deberá estar resuelto antes de 1990.” Lo estuvo: la invasión norteamericana se produjo en diciembre de 1989."10

El Santa Fe IV expresa abiertamente su vocación por revivir la guerra fría: “... la amenaza soviética ha desaparecido. No sólo nuestras fuerzas armadas se ven comprometidas por este cambio radical. También nuestra imagen de nosotros mismos. (...) Ahora que se ha superado la amenaza soviética, tenemos que reconstruir la nación. Pero sin ese peligro externo, nos puede faltar la identificación necesaria para salir adelante." 11

Un estudio crítico sobre el documento, a cargo de Beba Balvé y Carlos Suárez, señala entre sus autores, además de al general Summer Jr., al diplomático e historiador Lewis Arthur Tambs, profesor de la Arizona State University, al ex embajador estadounidense en Perú, David Jordan, y a un calificado grupo de asesores y especialistas del Center of Hemispheric Studies del American Enterprise Institute. ${ }^{12}$ Balvé y Suárez añaden que tales expertos "han estado vinculados a los grupos contrarrevolucionarios cubanos y a las organizaciones paramilitares de Guatemala y El Salvador” y son discípulos del profesor Nicholas Spykman, quien afirmó en su libro más reciente: "La guerra es la situación normal en las relaciones internacionales y la paz es sólo un armisticio entre la guerra que pasó y la que viene.”13

Con cierto ritualismo cabalístico, el Santa Fe IV identifica como los principales problemas lo que denomina 'las nueve D': Defensa, Drogas, Demografía, Democracia Populista, Desestabilización y Declinación de Estados Unidos. Finalmente plantea los principales elementos geoestratégicos para la seguridad de Estados Unidos: 1) control de los

${ }^{10}$ Miguel Bonasso, “Los enemigos de Bush”, Diario Página 12, 1 de junio de 2001.

${ }^{11}$ Documento del Comité de Santa Fe IV.

${ }^{12}$ Beba Balvé y Carlos Suárez, Santa Fe IV: una visión conspirativa, 2001, Buenos Aires, Ediciones del Polo Social.

${ }^{13}$ Nicholas Spykman, Estados Unidos frente al mundo. 
EDUARDO MOLINA

estrechos atlánticos; 2) uso del Canal de Panamá (“operado por compañías de cobertura de los chinos”); 3) una ruta sureña, segura, alrededor del Cabo de Hornos; 4) seguridad de que los países del hemisferio no son hostiles a las preocupaciones estadounidenses de seguridad nacional y de que sus recursos naturales ‘estén disponibles’. Y concluye: "Una Doctrina Monroe ('América para los /norte/ americanos’), si se quiere.”

\section{La narcoeconomía imperial}

El pensamiento de ultraderecha del Comité de Santa Fe busca defender un nuevo orden internacional del imperio globalizado cuya fachada legal e institucional es, más que nunca, sólo la parte visible de un iceberg. Por debajo, su base se rige por otras reglas y es alimentada por el dinero sucio del narcotráfico y otras actividades delictivas.

Se trata de un estado de cosas que, según informes de la Organización Internacional del Trabajo y de las Naciones Unidas, es responsable de que 4,000 millones de los 6,000 millones de personas que habitan el planeta no produzca ni consuma prácticamente nada, mientras el resto amenaza con agotar los recursos naturales en el curso del siglo XXI. ${ }^{14}$ Desigualdad social, concentración de la riqueza e irresponsabilidad ecológica que no hacen más que incrementarse desde el fin de la Segunda guerra mundial y particularmente a partir del colapso soviético, que eliminó el único contrapeso político internacional, así sea simbólico, frente a la tendencia a ahondar el abismo entre ricos y pobres. Pero además de ser una amenaza a la paz social, la sustentabilidad productiva y la equidad generacional, la superficie jurídico-política de ese orden cada vez más injusto poco tiene que ver con las relaciones económicas ilegales y las cadenas de lealtades y de protección de acciones ilícitas que le sirven como base de sustento.

\footnotetext{
${ }^{14}$ Informes anuales del Programa de las Naciones Unidas para el Desarrollo.
} 
En recientes declaraciones públicas el senador demócrata estadounidense Carl Levin, basándose en un consenso entre investigadores del Capitolio, ex banqueros y expertos internacionales, estimó que entre 500,000 millones de dólares y un billón de dólares de dinero sucio son anualmente lavados, transferidos internacionalmente y depositados en cuentas bancarias de Estados Unidos, Europa y otros países. Calculó que aproximadamente la mitad de esos fondos se 'blanquean' en bancos estadounidenses.

Según James Petras, profesor investigador de la Universidad del Estado de Nueva York, “durante la última década, entre 2.5 y 5 billones de dólares de procedencia criminal han sido lavados en Estados Unidos y se mueven en los circuitos financieros estadounidenses". ${ }^{15}$ Petras aclara que ese cálculo sólo cubre lo que se considera dinero de procedencia criminal según las leyes de Estados Unidos, y no incluye transferencias ilegales ni flujos de capital pertenecientes a líderes políticos o empresariales corruptos, ni la evasión fiscal de negocios en el extranjero.

Raymond Baker, experto en finanzas internacionales del Brookings Institute, estima que "el flujo de dinero corrupto proveniente del Tercer Mundo y de las economías ex comunistas aporta a las arcas occidentales entre 20,000 y 40,000 millones de dólares anuales, la mitad de los cuales termina en Estados Unidos, y agregó que los flujos provenientes de esos mercados subestimados representan, anualmente, 80,000 millones de dólares o más". ${ }^{16}$ Baker sostuvo: "Mi estimación más modesta es del orden de 100,000 millones de dólares al año provenientes de ambos casos, lo que da un billón de dólares en una década, que al menos en la mitad ha terminado en Estados Unidos; si se incluyen otros movimientos ilegales de capital, se llegará a una cifra mucho más elevada.” A juicio de Petras, los al menos 5.5 millones de dólares de procedencia criminal ingresados en las arcas estadounidenses en

15 James Petras, "Dinero sucio, cimiento del imperio y el crecimiento de Estados Unidos”, La Jornada, 19 de mayo de 2001, México.

${ }^{16}$ Testimonio de Raymond Baker ante el Congreso de los Estados Unidos. 
EDUARDO MOLINA

la década de los 90 cubrieron el déficit de unos 300,000 millones de dólares anuales de la balanza comercial de Estados Unidos. "Sin el dinero sucio - subraya- las cuentas de Estados Unidos en el extranjero serían insostenibles, los estándares de vida se desplomarían, el dólar se debilitaría y los capitales disponibles para el préstamo y la inversión se reducirían al grado de que Washington no podría mantener su imperio global." 17

Una idea del enorme peso relativo de la economía ilegal en la economía global lo da el hecho de que las ganancias por actividades criminales de diversos tipos, en especial el narcotráfico, exceden las de las principales empresas monopólicas transnacionales. Son asimismo superiores al monto de todas las transacciones de los principales productores de petróleo, la industria militar y las firmas fabricantes de aviones estadounidenses. Un alto porcentaje de los beneficios del Bank of America, J. P. Morgan, Chase Manhattan y en especial del Citibank, proviene de las cuentas de dinero criminal. Pese a los discursos políticos de lamentación, las leyes restrictivas aprobadas por los parlamentos y las resoluciones de organismos nacionales e internacionales, la influencia relativa del dinero sucio continúa aumentando. La red bancaria ha elaborado un complejo sistema de transferencias, cuentas secretas y procedimientos de protección que posibilitan el encubrimiento de enormes operaciones de ‘lavado’ de dinero. Mediante tales estructuras y dispositivos de carácter financiero logran transferir fondos ilícitos a sus cuentas en Estados Unidos, invertirlos en negocios lícitos o en bonos gubernamentales y, de ese modo, legitimarlos.

Los principales bancos estadounidenses hacen caso omiso de la legislación contra el 'lavado' y no son realmente investigados. Esta tolerancia oficial obedece sin duda a que son uno de los más importantes sostenes del imperio. No se trata de casos aislados o de excepciones sino de un verdadero sistema organizado desde la cúpula.

Un caso ejemplar es el encubrimiento por el Citibank de las operaciones ilegales, presuntamente vinculadas al narcotráfico, de Raúl

${ }^{17}$ Petras, ibid. 
Salinas (hermano del ex presidente mexicano Carlos Salinas). Detenido, procesado y condenado por el asesinato de su ex cuñado José Francisco Ruiz Massieu, secretario general del entonces oficialista Partido Revolucionario Institucional (PRI), Raúl Salinas gozaba de la protección de su corredora privada del Citibank, Amy Elliot, quien declaró a sus colegas con motivo de su involucramiento en el caso: "Esto llega muy, pero muy arriba de la corporación. Esto se sabía en los más altos mandos. Todos somos pequeños peones en todo este asunto."

El Citibank es uno de los principales bancos lavadores de dinero sucio y opera en 100 países con 180,000 empleados, 700,000 millones de dólares en cuentas regulares y 100,000 millones en cuentas privadas (es decir secretas). Son precisamente los bancos privados, con su servicio reservado a clientes especialmente prósperos (depósitos de un millón de dólares o más), los que poseen los más complicados sistemas de confidencialidad. Y son, obviamente, los que venden secreto al dinero sucio.

Los bancos privados usan cuentas en clave y cuentas de concentración donde los fondos de los clientes se fusionan con los del banco, ahorrando miles de millones de dólares en trámites y transacciones a distancia, además de no dejar rastros en papeleo. El Citibank ayudó a Salinas a sacar de México unos 100 millones de dólares disfrazando sus fuentes, creando una corporación fantasma en el extranjero, dándole una clave secreta, otorgándole un alias a un intermediario que depositó el dinero en la filial del banco en México y transfiriéndolo luego a una cuenta concentradora en Nueva York, que después trasladó los fondos a Suiza y Londres.

A su vez, las Corporaciones Privadas de Inversión (CPI) fueron diseñadas por los grandes bancos como otro recurso para esconder los bienes de una persona. De hecho las CPI poseen cuentas y carteras de clientes de bancos cuyos antecedentes se encuentran sepultados bajo la presunta jurisdicción de las autoridades de las Islas Caimán. Según Petras "banqueros privados de instituciones como el Citibank tienen ya varias CPI empacadas y listas para ser activadas cuando surja un nuevo 
EDUARDO MOLINA

cliente de banca privada. Este sistema funciona como las muñecas rusas Matryoshka: capas bajo capas de más capas que acaban formando un proceso legal impenetrable”. ${ }^{18}$

Hubo investigaciones, auditorías, críticas y leyes contra el lavado, los banqueros prometieron acatamiento, pero de acuerdo con el profesor Petras los diez principales bancos violan reiterada e impunemente la ley ante la tolerancia de las autoridades. El Congreso de Estados Unidos investigó la participación del Citibank en los escandalosos casos de Salinas, el marido de la ex primera ministra de Pakistán, Asif Alí Zardari, el dictador de Gabón El Hadj Omar Bongo, y los hijos del general Abacha, ex dictador de Nigeria. En ninguno de ellos se valoraron el perfil y los antecedentes, ni la fuente y legalidad de los ingresos. Por el contrario, el Congreso comprobó que hubo una clara complicidad en el encubrimiento. Sin embargo, ninguno de los funcionarios actuantes fueron investigados ni juzgados y el Citibank continuó moviendo fondos de dudosa procedencia a cuentas secretas y concediendo préstamos.

Un recurso adicional para blanquear dinero sucio son los bancos de correspondencia, que prestan servicios bancarios a otros bancos. Permiten a bancos de diversos países periféricos llevar a cabo negocios y dar servicio a sus clientes -incluidos narcotraficantes y otros personajes vinculados a actividades delictivas- bajo jurisdicción de países como Estados Unidos, pero en lugares donde sus bancos no existen físicamente. Se trata de bancos que cuentan con licencias en un país extranjero y no tienen oficinas estadounidenses, pero que pueden abrir su cuenta en un banco estadounidense y de ese modo atraer a la próspera clientela criminal del exterior interesada en lavar dinero en Estados Unidos.

Los principales bancos europeos y estadounidenses han montado una red mundial de miles de bancos de correspondencia y se especializan en transferencias telegráficas internacionales de fondos que llegan a montos de hasta un billón de dólares diarios. En junio de 1999 el

${ }^{18}$ Ibid. 
balance de los 75 principales bancos estadounidenses de correspondencia ascendió a casi 35,000 millones de dólares. De acuerdo con estimaciones efectuadas en 1998, unas 60 jurisdicciones extranjeras autorizaron a 4,000 bancos el control sobre aproximadamente 5 billones de dólares en distintos bienes. ${ }^{19}$

El pillaje de la economía y los miles de millones de dólares que se fugan anualmente de los países dependientes a través de los sistemas bancarios de correspondencia y los servicios bancarios privados relacionados con los principales bancos europeos y estadounidenses, constituyen una de las principales causas de la pobreza y el estancamiento del mundo periférico, generando miseria masiva, inestabilidad, crisis y violencia. Otra de las consecuencias de esta situación es una mayor vulnerabilidad ante las presiones del Fondo Monetario Internacional (FMI) y el Banco Mundial (BM), que fuerza a las naciones dependientes a liberalizar sus sistemas bancarios y financieros. El resultado es una disminución de controles y directrices que promueve un aumento de la corrupción y mayores transferencias de riquezas al exterior, según lo revelan los informes sobre el tema elaborados por el Senado de los Estados Unidos.

Petras sostiene que "la creciente polarización del mundo se encuentra arropada en un sistema de crimen organizado y de transacciones financieras corruptas; mientras que la especulación y el pago de deudas externas son elementos que contribuyen a reducir los estándares de vida en regiones en crisis, el lavado multimillonario de dinero es un factor de la mayor importancia, puesto que también sirve para apuntalar la prosperidad del imperio de Estados Unidos”. ${ }^{20}$

Y concluye: "La magnitud, los espacios y los tiempos de estas transferencias y de estos lavados de dinero, el centralismo de las más grandes instituciones bancarias y la complicidad de los gobiernos, sugiere que en la dinámica del crecimiento y el estancamiento, el imperialismo y la recolonización están íntimamente relacionados con una nueva forma

${ }^{19}$ Informes estadísticos del Departamento del Tesoro de Estados Unidos. ${ }^{20}$ Op. cit. 
EDUARDO MOLINA

de capitalismo construido en torno al pillaje, el crimen, la corrupción y el contubernio."21

\section{Las recetas letales}

Este dispositivo de explotación y saqueo se completa con las recomendaciones que imponen periódicamente el Fondo Monetario Internacional y el Banco Mundial, que sólo sirven para agravar las recurrentes crisis económicas de los países pobres que supuestamente pretenden resolver.

En un reciente artículo, el periodista británico Gregory Palast se basó en entrevistas con Joseph Stiglitz - ex vicepresidente y economista jefe del Banco Mundial, que desertó desde posiciones duramente críticas-, así como en otros datos y apreciaciones que aportaron diversos contactos, para trazar un cuadro de las estrategias que suelen acordar el BM, el FMI y el Tesoro de Estados Unidos (dueño del 51\% del FMI) para presuntamente 'ayudar' a los países que caen en crisis. ${ }^{22}$

El BM sostiene que elabora planes de recuperación específicos caso por caso, como resultado de un cuidadoso estudio de las condiciones que se presentan en cada momento y lugar. Stiglitz sostiene, en cambio, que los representantes de la entidad financiera mundial que son enviados a simular una investigación in situ se limitan a alojarse en hoteles de cinco estrellas, entrevistarse con las serviles autoridades económicas locales y firmar acuerdos de reestructuración de deudas y créditos redactados con anticipación.

De acuerdo con el artículo, los cuatro pasos (conocidos bajo el jocoso nombre de ‘mambo monetario') empiezan con la imposición de privatizaciones. Según Stiglitz, que presidió el consejo de asesores económicos del presidente estadounidense Bill Clinton entre 1993 y 1997, en general los interlocutores de los países dependientes, en vez de oponer-

${ }^{21}$ Ibid.

${ }^{22}$ Gregory Palast, “Los cuatro pasos del FMI hacia la perdición”, The Observer, 20 de mayo de 2001, Londres. 
se a entregar las empresas públicas por precios de remate a los monopolios transnacionales del primer mundo, aprovechan la presión del BM para silenciar a la oposición local, al tiempo que "les brillan los ojos ante la oportunidad de embolsar sustanciosas comisiones”.

El segundo paso es la imposición de la liberalización del mercado de capitales, en teoría para que los fondos de inversión puedan entrar y salir del país sin obstáculos. Muchas veces, dice Palast, esos capitales simplemente se van. Al describir este 'ciclo del dinero caliente’, según su propia expresión, Stiglitz sostiene que esos capitales entran para la especulación cambiaria e inmobiliaria y huyen al primer asomo de dificultades, vaciando y conmoviendo las reservas monetarias del país afectado. Entonces el FMI ordena elevar las tasas de interés al máximo y se completa un nuevo desastre.

El tercer paso -prosigue Stiglitz- consiste en imponer precios de mercado, en lugar de políticos, para así aumentar el costo de alimentos, garrafones o agua potable, lo cual provocará probables disturbios (a los que Palast describe como demostraciones pacíficas dispersadas con balas, tanques y gases lacrimógenos), recordando los casos de Indonesia y más recientemente los de Bolivia y Ecuador. Su artículo señala que el plan para dolarizar Ecuador sumió bajo la línea de pobreza a más de la mitad de la población. Del lado de los beneficiarios de estas políticas aparecen natural e invariablemente los bancos de los países centrales y el Tesoro de Estados Unidos.

Y por último el cuarto paso al desastre que recetan el FMI y el BM es la instauración de un libre intercambio irrestricto según las reglas de la Organización Mundial de Comercio (OMC). Bajo estas normas los monopolios transnacionales europeos y estadounidenses destruyen las barreras protectoras de los países dependientes, al mismo tiempo que cierran la entrada a sus mercados de los productos agropecuarios y otras mercancías de esa procedencia. Palast dice que tal como en la Guerra del Opio de Gran Bretaña contra China (1840-1842), para forzar el ingreso del estupefaciente al país asiático, en la actualidad las potencias imperialistas dominantes disponen de la posibilidad de sitiar a los que no acepten sus políticas y sus condiciones económicas. Los 
EDUARDO MOLINA

bloqueos militares del siglo XIX han sido sustituidos hoy por el Grupo de los 8 con la amenaza o el empleo de un bloqueo o sitio financiero tanto o más eficaz y aniquilador.

A nivel de la manipulación de la opinión pública internacional, el ‘pensamiento único' también controla y maneja de forma monopólica y excluyente una poderosa e hipertecnificada red global de medios de difusión que tapa casi por completo las voces y las opiniones disidentes, o se limita a exhibirlas como trofeos etiquetados con el sello de una pretendida 'libertad de expresión'.

Y es que también en este plano de las libertades públicas y las garantías individuales, que fueron siempre banderas predilectas de los ideólogos de la iniciativa privada, la sociedad de mercado está fracasando rotundamente.

\section{El fin de la privacidad}

La redoblada concentración monopólica transnacional, el incremento de las desigualdades sociales y la necesidad de prever y reprimir los inevitables estallidos de rebeldía, características básicas del mundo global bajo el capitalismo imperial, así como la intensa revolución científico tecnológica en pleno auge (cuyos exponentes más notorios son los impresionantes desarrollos en ingeniería biológica, cibernética, telecomunicaciones y computación), están conduciendo a un creciente proceso de destrucción de la privacidad de las personas. Según el periodista Simson Garfunkel, el libre mercado y el desbordante intercambio de información electrónica son las causas inmediatas del amenazante fenómeno. ${ }^{23}$

Pronto la biotecnología posibilitará seleccionar personal previendo destinos genéticamente determinados con décadas de anticipación, y ya hace años que cientos de satélites artificiales revisan hectárea por hectárea toda la superficie de nuestro planeta, ubicando y distinguiendo

${ }^{23}$ Simson Garfunkel, Database Nation, 2001, Washington. 
detalles del tamaño de una baldosa. Un reciente sondeo de la cadena radiotelevisiva National Broadcasting Company (NBC) y el matutino The Wall Street Journal reveló que la pérdida de la privacidad preocupa más a los estadounidenses que la sobrepoblación, las tensiones raciales y el calentamiento atmosférico. Por otra parte, Estados Unidos posee, proporcionalmente al conjunto de sus habitantes, la población carcelaria más numerosa del mundo. El ciudadano común teme opinar por miedo a ser escuchado por algunos de los múltiples organismos de espionaje al servicio del estado, las empresas o particulares. Crecen la contratación de guardaespaldas y la compra de aparatos trituradores de papeles y documentos. Libros recientes como Database Nation (Nación Archivo), de Simson Garfunkel, El indeseable acecho, de Jeffrey Rosen, El fin de la privacidad, de Reg Whitaker y La cultura de los soplones: cómo los ciudadanos son convertidos en los ojos y los oídos del estado, de Jim Redden, expresan la preocupación de los formadores de opinión estadounidenses por un futuro que parece amenazar con un capitalismo digno de la novela 1984, del escritor inglés George Orwell, siniestro cuadro de un sistema con total control de la intimidad de los individuos, paradójicamente inspirado en la pesadilla stalinista. $^{24}$

Agencias de gobierno, grupos privados no lucrativos y empresas especializadas vigilan a decenas de millones de personas en Estados Unidos y Europa, compartiendo la información entre sí, con sus clientes y con el Estado. Dos tercios de las grandes empresas monitorean el correo electrónico y el uso de internet de sus empleados, mantienen cámaras de video ocultas y siguen el movimiento del personal en los centros de trabajo. Los sindicatos ignoran el tema y la Unión Americana de Libertades Civiles, si bien investigó y reclamó, no pudo persuadir a los patrones de que cesen de meterse en la vida personal de la gente, ni a los congresistas de que legislen en la materia para evitarlo.

${ }^{24}$ Fernando Velázquez, Estados Unidos: la cultura de los soplones, artículo distribuido por el Servicio Informativo ALAI-AMLATINA, revista Memoria, mayo de 2001. 
EDUARDO MOLINA

Así como en los inicios de la revolución industrial el espionaje de empresas y agencias de gobierno se dirigía contra el naciente sindicalismo y después, durante los siglos XIX y XX, se orientó también hacia las organizaciones y las luchas de los anarquistas, socialistas y comunistas, bajo las actuales circunstancias su blanco es el amplio y combativo movimiento mundial de resistencia civil contra la globalización imperial. Seattle, Davos, Praga y Génova fueron hitos que marcaron la creciente rebeldía contra las políticas del Grupo de los 8, el FMI, la OMC y el BM. Durante los últimos años el FBI y las policías de todos los países centrales se han jactado de haber infiltrado al movimiento, al que tratan como si fuera de carácter terrorista, introduciendo en sus filas no sólo informantes sino también violentos provocadores que ‘justifican’ las escaladas represivas.

El experto y articulista del Portland Tribune Jim Redden reveló en un libro reciente dos nuevos sistemas de espionaje moderno, el 'carnívoro’ y el ‘echelon'. ${ }^{25}$ Mediante el sistema ‘carnívoro’, el FBI lleva una computadora a la oficina del servidor/proveedor de internet, la conecta a la computadora del proveedor y hace un 'download' (una copia) de todo lo que está allí guardado. El pretexto es que el Buró Federal de Investigaciones está vigilando las actividades de criminales que usan internet, sin embargo, el contenido total de la computadora del proveedor es ‘vaciado’ o copiado, incluida la información no sólo de posibles delincuentes sino de todos los demás clientes o usuarios.

El sistema 'carnívoro' estuvo en operaciones sin mayores problemas todo un año, antes de que la prensa tropezara con la noticia de su existencia cuando el FBI cometió el error de dar una breve explicación de su uso a unos empleados ejecutivos de la industria de computadoras, quienes después lo revelaron a la prensa.

En cuanto al 'echelon', Redden lo describe como el símbolo de un masivo e invasor espionaje gubernamental. Es de carácter global e incluye satélites, flotas de aviones militares, submarinos, y otros recur-

${ }^{25}$ Jim Redden, La cultura de los soplones: cómo los ciudadanos son convertidos en los ojos y los oídos del estado, 2000, Portland. 
sos que ni siquiera se conocen públicamente. Se trata de una red capaz de recolectar virtualmente todas las transmisiones electrónicas que surcan el espacio en cualquier momento: teléfonos celulares, faxes, mensajes de correo electrónico, transmisiones de radio de onda corta. Aspectos generales del sistema ‘echelon’ fueron revelados por la revista Covert Action Quarterly de Washington al informar, con gran escándalo de los aliados del otro lado del Atlántico, que la Agencia Nacional de Seguridad de Estados Unidos espía a las corporaciones europeas y pasa enormes volúmenes de datos reservados a sus competidores estadounidenses. La cobertura oficial del ‘echelon’ pretende, obviamente, que "es un sistema para controlar las actividades de narcotraficantes y terroristas".

\section{El ‘nuevo socialismo' del profesor Peters}

La recomposición de propuestas globales de las fuerzas socialistas, la izquierda y en general el campo popular -que en la última década asumieron una estrategia básicamente defensiva y no lograron contrarrestar de modo eficaz la hegemonía prácticamente total del llamado 'neoliberalismo'- deberá pasar por un complejo proceso dialéctico teórico-práctico, donde la autocrítica del pasado reciente y el surgimiento de nuevos conceptos deberá probarse e interactuar con las movilizaciones y las luchas concretas en el escenario político mundial. Ninguna respuesta eficaz podrá salir sólo de las elaboraciones exclusivamente intelectuales o de las acciones anticapitalistas más o menos espontáneas.

El movimiento de oposición a la globalización imperial que jaqueó la reunión del Grupo de los 8 en Génova se perfila por ahora como el referente principal a nivel de la lucha popular en escala mundial, y en ámbitos nacionales surgen y se desarrollan formas de resistencia inéditas como las movilizaciones de los piqueteros que practican cortes de rutas contra el desempleo en Argentina, los campesinos sin tierra en Brasil y el zapatismo en México. 
EDUARDO MOLINA

Mientras tanto y paralelamente surgen elaboraciones teóricas que aspiran a convertirse en "el nuevo proyecto histórico de las mayorías”, como la que se debe al economista e historiador alemán Arno Peters, quizá una de las más novedosas y polémicas creaciones intelectuales contemporáneas desde el campo de la izquierda.

Los lineamientos generales de esta concepción han sido desarrollados en su reciente libro Bases del nuevo socialismo por el profesor Heinz Dieterich Steffan, doctorado en Ciencias Sociales y Economía en la República Federal Alemana y desde hace diez años residente en México. Lo que intenta presentar esta obra es "otra forma de socialismo”, o si se quiere un nuevo modelo de 'democracia participativa', sobre la base de la idea de que "los conceptos históricos sobre el socialismo están perimidos”.

Más interesante tal vez por el debate que pueda suscitar y los resultados de su confrontación con la práctica política que por ser un modelo definitivo y acabado, la propuesta de Peters y Dieterich postula concepciones originales de justicia y solidaridad que apuntan a rescatar de su actual caricatura al concepto de democracia mediante la implementación real y concreta de la participación popular. ${ }^{26}$

Cierto voluntarismo de la inteligencia, muy germánico, se aprecia no sólo en el conjunto del modelo teórico de Dieterich sino también, de modo especial, en su afirmación -durante una entrevista con el periodista Luis Bruschtein- en el sentido de que “en 1950, en la URSS, el partido debería haber abandonado el papel de sustitución y entregar gradualmente las decisiones a la clase obrera”. ${ }^{27}$

En su libro, Dieterich descarta los conceptos de valor de uso y valor de cambio que utilizaban de diverso modo los teóricos clásicos socialistas y capitalistas. Con sustento en las elaboraciones del profesor e investigador Peters, desarrolla su complejo concepto de 'valor objetivo’, asimilable, pero sólo por simplificación, al de ‘tiempo de trabajo’.

${ }^{26}$ Cfr. Heinz Dieterich, Bases del nuevo socialismo.

${ }^{27}$ Luis Bruschtein, “El nuevo proyecto histórico de las mayorías”, entrevista a Heinz Dieterich, Diario Página 12, 5 de julio de 2001, Buenos Aires. 
El valor objetivo de las mercancías se obtiene a través de complicados cálculos matemáticos que suman el esfuerzo laboral y los insumos -y a su vez, el valor de éstos- requeridos para la producción de un bien, desde la extracción de la materia prima hasta la fase final.

‘Nuevo socialismo’ y ‘democracia participativa’ son términos usados como sinónimos. Pero la expresión 'nuevo socialismo’, aclara Dieterich, "es un puente hacia los veteranos de batallas anteriores que tienen su corazón en las diferentes vertientes del socialismo y andan algo dispersos". A su juicio "es necesario dialogar con ellos para que los contenidos del viejo socialismo y los de la revolución burguesa -libertad, igualdad, fraternidad-se puedan reactivar con vistas a potenciar las fuerzas de cambio actuales”.

"El sistema propuesto -explica- utiliza la economía nacional de mercado, que tiene como seis mil años de antigüedad y sólo en su última etapa se convirtió en una economía capitalista.” Y añade: “El elemento principal de la nueva civilización es la economía democráticamente planificada de equivalencias, sobre la base de la teoría del valor objetivo."

Según Dieterich tal teoría logra hacer operativo y práctico, gracias a la aparición de las computadoras y los nuevos desarrollos de las matemáticas, lo que desde hace doscientos años aproximadamente, a través de las teorías de David Ricardo, Adam Smith y Karl Marx, se sabía acerca de que el valor efectivo de las mercancías es dado por el tiempo de trabajo (socialmente) invertido en su producción. La determinación del valor objetivo de las mercancías, así posibilitada, facilitaría la planificación democrática de la economía.

En opinión del economista alemán el viejo socialismo fue una idea que se adelantó dos siglos a las condiciones objetivas para su realización, al igual que algunos teoremas de Albert Einstein sólo pudieron comprobarse empíricamente en la práctica científica cincuenta u ochenta años después de su enunciación. Por ejemplo, el socialismo es la autodeterminación de la gente, y por supuesto implica una democracia real participativa. Naturalmente tal democracia requiere mecanismos de comunicación eficientes, económicos, rápidos, que permitan 
EDUARDO MOLINA

expresar la voluntad de las mayorías de modo indiscutible y casi instantáneo, lo que se ve posibilitado ahora con internet, las computadoras y demás adquisiciones tecnológicas, capaces de hacer realidad una especie de democracia plebiscitaria.

Dice Dieterich: "Si por ejemplo queremos saber cómo estructurar el presupuesto, se discute dos o tres meses en la televisión y los medios y, sobre esa base informativa y deliberativa, se aprieta un botón en la computadora y, sin mayor costo ni demora, se sabe lo que quiere la gente para el próximo año. La idea de la nueva economía sobre la base del valor objetivo, como la de la democracia participativa no tenía antes una correspondencia empírica.”

Ante la pregunta de Bruschtein acerca de si el ejercicio real de la democracia no dependería en ese caso de quién es el propietario de los medios de comunicación, explica que habría que diferenciar la fase final, que Marx llamaba el reino de la libertad, la sociedad sin clases, de la fase de transición. Peters sólo plantea y discute el principio de la economía de equivalencia, como él denomina a la basada en el concepto de valor objetivo, para la fase final, y Dieterich admite que en la fase de transición hay que hacer ciertas modificaciones, compromisos entre justicia y eficacia en la economía, para que no se produzcan migraciones indeseables de profesionales y mano de obra como resultado de los desequilibrios heredados. "Tienen que ser las mayorías las que decidan las áreas sociales, económicas, culturales o militares en las que se deba ir introduciendo la democracia participativa, extendiéndose gradualmente hasta cambiar la lógica del sistema”, afirma.

En opinión de Dieterich ni la vertiente leninista del socialismo ni la socialdemócrata se verían continuadas linealmente en el socialismo del futuro. Sostiene que cuando Lenin estableció que la clase obrera, que según los clásicos sería el sujeto principal del cambio, debía ser conducida por un partido de cuadros profesionales, en realidad sustituyó de hecho al sujeto del cambio. En 1950, después de treinta años, la URSS ya no era un país de campesinos analfabetos como en 1920, y había como 40 millones de trabajadores industriales. "Hubiera tenido que revertir el argumento anterior -fantasea Dieterich-y decir: como 
la clase obrera industrial ya está apareciendo con fuerza tremenda el partido deja el papel de sustitución y entrega gradualmente las decisiones a la clase obrera. Pero eso nunca sucedió y, por lo tanto, en los socialismos realmente existentes sólo hubo un avance en la dimensión de la justicia social, pero no democratización. Cuando el sistema soviético adquirió complejidad y, de ser una sociedad agraria, pasó a convertirse en una sociedad de alta tecnología, entre los años 70 y 80, sufrió una crisis de acumulación, sumada a una crisis de democratización, crisis que no se resolvieron y la llevaron al colapso.”

En cuanto a la propiedad de los medios de producción Dieterich señala que en el nuevo socialismo no se aplicaría ni la línea socialdemócrata o del cepalismo de Raúl Prebisch, de dejar los medios de producción en manos de los empresarios y por vía fiscal extraerles parte de la plusvalía para repartirla, ni la estatización total preconizada por Marx y Engels para quitarle a la clase patronal el instrumento de la apropiación indebida del excedente económico.

“Como se podrá medir el valor objetivo de un producto y por lo tanto también el valor del esfuerzo del trabajo -razona- tendremos la base científica para ser justos; la segunda condición es que todos los que hacen el mismo esfuerzo laboral reciban la misma gratificación, porque el valor de su trabajo es equivalente y por justicia deben recibir la misma gratificación.”

Matizando, el autor de Bases del nuevo socialismo admite que en la fase de transición habría que diferenciar cuándo se trata de trabajo manual simple y cuándo de trabajo calificado, profesional o técnico, limitando las diferencias entre salarios altos y bajos como lo hizo el socialismo real, aunque en la fase final el director de una empresa que trabaja 40 horas recibiría lo mismo que el obrero que trabaja el mismo tiempo. Se trata de un proceso pensado para empezar por regiones hacia una nueva civilización poscapitalista, por lo cual debe resolver problemas prácticos orientados a no perder a la gente preparada.

El sujeto de cambio del 'nuevo socialismo' estaría conformado por el conjunto de todos los excluidos y los que por ética o sentido común no deseen ser cómplices de un mundo injusto e irracional. Entre los 
EDUARDO MOLINA

excluidos de América Latina estarían, por ejemplo, los 150 millones de pequeños campesinos desplazados por la penetración del capitalismo monopólico transnacional con la agroindustria, las decenas de millones de trabajadores industriales cuyo nivel de vida se deteriora aceleradamente desde hace décadas y el también numeroso pequeño y mediano empresariado, lo que suma alrededor de 200 millones de personas. "Cuando esa gente pierde su base de subsistencia -añade Dieterichse integra al ejército de desempleados y subempleados y se encuentra con los sujetos sociales no clasistas, con los 80 millones de afroamericanos, absolutamente marginados, se encuentra con 50 millones de indígenas también postergados, se encuentra con las amas de casa que no tienen reconocimiento de su valor económico... Éstos son los excluidos que tienen un interés vital por cambiar las cosas. Por otro lado están los intelectuales que por ética no quieren ser cómplices de un sistema tan brutal. Tales son los sujetos que cambiarían esta realidad.”

Dieterich subraya que el Manifiesto Comunista de 1848 fue un programa regional de lucha que se basaba en la semejanza de las condiciones de vida y la homogeneidad cultural de la clase trabajadora europea, lo que creaba la posibilidad de que lucharan en los diferentes países del área por un mismo proyecto de transformación social. En cambio, observa, hoy el trabajador alemán es de hecho clase media baja, completamente diferente que el de México o Argentina, y la unión entre esas clases sociales es casi imposible. Al mismo tiempo señala que si bien en América Latina la identidad del habitante de una nación indígena es muy diferente a la de un trabajador industrial, "tienen un elemento en común, que es que no tendrán condiciones de vida adecuadas en este modelo neoliberal porque sus leyes de mercado y las de sus países están hechas para los grandes, no para los pequeños...”.

El ‘nuevo socialismo' aspira a convertir al Estado en una convivencia multicultural, multiétnica, porque el Estado nacional actual nace metiendo en una camisa de fuerza a diferentes naciones, mientras que hoy, por diferentes razones, podríamos convivir en un Estado federal, democrático y respetuoso de las identidades de los diversos grupos. 
A juicio del teórico alemán las condiciones objetivas de un cambio como el que propone se están dando, porque el propio sistema imperial se concentra cada vez más: el 84 por ciento de la riqueza mundial está en el primer mundo y excluye a 5,000 millones de seres humanos. "Un sistema así - dice- no puede ser estable. Lo que faltan son las condiciones subjetivas. Es decir, no ha habido un proyecto histórico de cambio.”

Para estructurarlo considera necesario entender cuáles son las instituciones constitutivas de la nueva civilización, que ya no pueden ser, como en la sociedad burguesa, el mercado capitalista, la democracia sólo formal y el individuo tomado aisladamente.

Explica que "la economía nacional de mercado ya no cumple su función de satisfacer las necesidades de la gente, porque cada vez hay más gente en la miseria; la democracia formal sufre una fuerte involución, como se vio en el robo de las elecciones en Estados Unidos. La plutocracia liquida esos mecanismos formales y no puede dar espacio a la democracia participativa. Así, el sujeto racional y ético será cada vez más peligroso porque cuanto más crece la productividad del trabajo hay más excluidos. Se está peor en vez de mejor y una persona ética va a protestar. Entonces el sistema tiene cada vez mayor necesidad de controlar las mentes y de conceder menos libertad en lo cultural y lo político. Estas instituciones están agotadas estructuralmente”.

En lo relativo a cuáles serían las nuevas instituciones que vendrían a reemplazarlas, Dieterich las describe como un trípode sustentado en una nueva base productiva: "En el plano económico sería la economía democráticamente planificada. Se trata de una economía que no está basada en el principio destructivo de la competencia, porque si le gano a otro, quiere decir que lo destruí económicamente. En el plano político hay que entender a la democracia como la propiedad fundamental del nuevo sistema social. Esta característica tiene tres dimensiones, que son la democracia formal, la democracia social y la democracia participativa. De esas tres dimensiones de la democracia, en la sociedad burguesa sólo hay una realizada a medias en los estados del primer mundo. La democracia participativa mejora e integra a la democracia 
EDUARDO MOLINA

formal. Estas dos instituciones, la economía democráticamente planificada y la democracia participativa, crean el entorno para que el sujeto pueda ser lo que siempre ha querido ser en la filosofía burguesa: un sujeto completo, racional por la ciencia, ético y estético. Éstas serían las tres columnas sobre las cuales se construiría la civilización poscapitalista.”

\section{Un debate abierto}

Las ideas de Peters-Dieterich parecen pecar de cierto utopismo racionalista. ¿Pero podría ser de otro modo un intento teorizador semejante en las actuales condiciones de reflujo de las luchas populares y de quiebre de los modelos conceptuales tradicionales del socialismo?

Podemos dudar de la posibilidad y la eficacia de un sistema de consulta plebiscitaria permanente de los asuntos públicos, o de una medición exacta del valor objetivo de las mercancías y la consiguiente remuneración precisa e igualitaria, basada en los tiempos de trabajo, de los múltiples, complejos y disímiles esfuerzos y talentos laborales que ellas encierran, así como de la pertinencia de intentar, una vez más, producir un cambio global a partir de cambios parciales, regionales y graduales. Sin embargo, nada nos autoriza a desechar la fecundidad teórico-práctica que puede tener un debate donde se formularan éstas y otras propuestas renovadoras del arsenal intelectual de la izquierda para afrontar la presente coyuntura histórica.

Resulta vital este tipo de aportes enriquecedores mientras, desde múltiples ángulos, la protesta y la rebelión contra el actual estado de cosas crece y se diversifica en todos los rincones del planeta a través de un contradictorio proceso dialéctico que incluye también a las nuevas elaboraciones teóricas y apunta a síntesis sucesivas capaces de renovar la esperanza. 